\title{
DETECÇÃO DE BACTERIOCINAS PRODUZIDAS POR BACTÉRIAS FITOPATOGÊNICAS DOS GÊNEROS Erwinia, Pseudomonas e Xanthomonas
}

\author{
C.M.R. de BIAGI ${ }^{1}, 2$ \&.L. de AZEVEDO ${ }^{2}$
}

RESUMO: A deteç̧ão da produção de bacteriocinas foi estudada em diferentes condições, utilizando-se linhagens de bactérias fitopatogênicas dos gêneros Erwinia, Pseudomonas e Xanthomonas. Obtiveram-se, respectivamente, $58,06 \%, 71,31 \%$ e $40,00 \%$ de linhagens produtoras no meio 523 , que foi o mais indicado para detecção dessa produção. Uma maior concentração de ágar adicionada ao meio $(1,5 \%)$ produziu melhores resultados mas, a quantidade de meio nas placas não influenciou a detecçāo de bacteriocinas. O maior tempo de incubação utilizado (72 h.) facilitou deteç̧ão de halos de produção de bacteriocinas. Irradiação com luz ultra-violeta em baixas doses parece facilitar a liberação de bacteriocinas, mas isso varia com a linhagem empregada.

Descritores: Bacteriocinas, Xanthomonas, Pseudomonas, Erwinia.

\section{DETECTION OF BACTERIOCINS PRODUCED BY PLANT PATHOGENIC BACTERIA FROM THE GENERA Erwinia, Pseudomonas and Xanthomonas.}

ABSTRACT: Detection of bacteriocin production was studied under distinct conditions using strains of plant pathogenic bacteria from the genera Erwinia, Pseudomonas and Xanthomonas. $58.06 \%, 79.31 \%$ and $40.00 \%$ of producing strains were found respectivelly in the three groups of bacteria using the 523 medium which was the best for the detection of bacteriocin production. Increasing agar concentrations added to the medium up to 1,5\% improved the detection. The amount of medium added to the Petri dishes did not affect bacteriocin production. The longest incubation time (72h.) improved the detection of haloe production. Ultra-violet irradiation in low dosages seems to improve the visualization of haloe prodution but this is dependent on the tested strains.

Key Words: bacteriocins, Xanthomonas, Pseudomonas, Erwinia.

\section{INTRODUÇÃO}

Bacteriocinas são proteínas produzidas por bactérias possuidoras de elementos extracromossômicos, denominados de plasmídios bacteriocinogênicos. Essas proteínas atuam como antibióticos de espectro muito reduzido, atacando apenas algumas bactérias da mesma espécie ou espécies correlatas. Revisões a respeito são encontradas em DAY (1990) e ROITMAN et al., (1992). Com o advento da tecnologia do DNA recombinante, a deteç̧ão de bactérias contendo plasmídios, inclusive bacteriocinogênicos, tornou-se extremamente importante pois, sendo eles potenciais veículos ou vetores de genes, a descoberta e posterior isolamento desses plasmídios em bactérias pouco exploradas geneticamente, poderia permitir seu estudo mais aprofundado das mesmas por novas tecnologias.
Revisões sobre a importância de plasmídios como vetores em Engenharia Genética, são encontrados em AZEVEDO (1985), PRIMROSE (1987) e COSTA (1987). Além disso, tem-se também preconizado o uso de bactérias produtoras de bacteriocinas, no controle de bactérias patogênicas, desde que sua patogenicidade seja atenuada. Finalmente, com a possibilidade de manipulação genética em microrganismos endofíticos, genes para produção de bacteriocinas têm possibilidade de serem introduzidos no mesmo ou nas plantas, conferindo uma proteção contra outros microrganismos patogênicos.

Assim, não só do ponto de vista acadêmico como também aplicado, linhagens produtoras de bacteriocinas têm recebido especial atenção, e sua detecção das mesmas vem adquirindo importância cada vez maior. Sabe-se que a produção e liberação dessas

\footnotetext{
${ }^{1}$ Departamento de Genética, ESALQ/USP, Caixa Postal, 83 - 13418-900-PIRACICABA-SP.

${ }^{2}$ Endereço Atual: Faculdade de Ciências Biomédicas, 13600-ARARAS-SP.
} 
substâncias podem ser influenciadas em diferentes espécies por fatores como: tipo de meio de cultivo, aeração, ciclo de crescimento e fatores físicos como luz ultra-violeta, entre outros. $O$ presente trabalho teve por objetivo otimizar as condições para deteç̧ão de bacteriocinas em bactérias fitopatogênicas dos gêneros Erwinia, Pseudomonas e Xanthomonas.

\section{MATERIAL E MÉTODOS}

Linhagem e meios de cultura: Foram utilizadas 80 linhagens de bactérias dos gêneros Erwinia (E-1 a E31), Pseudomonas (P-32 a P-60), e Xanthomonas (X-61 a X-80) isoladas de hortaliças infectadas. As bactérias foram estocadas no Setor de Genética de Microrganismos do Departamento de Genética da ESALQ/USP. Os meios de cultura utilizados foram o nutriente ágar (NA) da Difco, meio 523, preparado segundo KADO \& HESKETT (1970) e o meio TYAgar (TYA), preparando segundo STANGHELLINI $e t$ alli (1977).

Produção de bacteriocinas em meio sólido: A presença ou ausência de bacteriocinas nas linhagens foi detectada pela técnica de AZEVEDO \& COSTA (1973), utilizando-se os meios sólidos NA, TYA e 523. Para o meio 523 foram também utilizadas duas concentrações de ágar ( $1 \%$ e $1,5 \%$ ), bem como diferentes quantidades de meio de cultura por placa (10 $\mathrm{ml}$ e $20 \mathrm{ml}$ ). Também a leitura em meio 523 foi feita após 24,48 e 72 horas de crescimento da linhagem produtora. A temperatura de incubação em todos os casos foi de $28^{\circ} \mathrm{C}$.

Indução de bacteriocinas com luz ultra-violeta: Foi utilizada uma fonte de luz ultra-violeta com comprimento de onda de $253 \mathrm{~nm}$ (mineralight UV lamp, modelo UVSL25). Para verificar a indução em meio líquido, linhagem produtora de bacteriocina foi incubada em meio 523 líquido, por 24 horas. Após centrifugação, o precipitado bacteriano foi suspenso $\mathrm{em}$ solução salina e irradiado a $7,0 \mathrm{~cm}$ da fonte por 10,20 e 30 segundos. Bactérias irradiadas foram incubadas com alça de platina calibrada, em 4 pontos de placa de Petri com meio 523 sólido, incubando-se as placas por 24 horas; as bactérias foram, a seguir, mortas com vapores de clorofórmio. Após evaporação do clorofórmio foram adicionados $5 \mathrm{ml}$ de meio $523 \mathrm{semi}$ sólido $\left(0,75 \%\right.$ ágar) a $45^{\circ} \mathrm{C}$, contendo linhagem sensível à bacteriocina (linhagem indicadora). Após incubação por 24 horas o diâmetro do halo de inibição foi medido. Um controle foi feito, sem irradiação. Para se verificar a indução em meio sólido, a bactéria produtora foi inoculada em 4 pontos de placa de Petri contendo meio 523 sólido, e incubou-se por 24 horas, após o que, irradiaram-se placas por 10, 20 e 30 segundos. Foi feito também um controle, sem irradiação. Após 2 horas, um lote de placas foi submetido aos vapores de clorofórmio e adicionou-se a bactéria indicadora, como descrito anteriormente. Outro lote de placas foi submetido ao clorofórmio, somente após permanência por 24 horas no escuro. Apb́s incubação por 24 horas, os halos de inibição foram medidos.

Produção de bacteriocinas em meio líquido: Amostras produtoras de bacteriocinas foram crescidas em $10 \mathrm{ml}$ de meio 523 líquido, com e sem aeração, por 24 e 48 horas, após o que, clorofórmio (1\%) foi adicionado ao meio, seguindo-se centrifugação e filtração do sobrenadante em filtro milipore (65 WPO 2500). Gotas do filtrado sem diluir e com diluição até 1:10.000 foram adicionadas às placas contendo meio 523 sólido já adicionado de bactérias indicadoras. Após incubação por, no mínimo 24 horas, foi feita a leitura verificandose a existência ou não de halo de inibição ao redor do filtrado.

\section{RESULTADOS}

A Tabela 1 apresenta os dados de produção de bacteriocinas pelas 80 linhagens ensaiadas nos 3 meios sólidos utilizados. Os resultados mostram que o meio 523 foi superior aos demais na deteç̧ão de bacteriocinas produzidas pelas bactérias usadas. Pseudomonas e Erwinia apresentam um número de linhagens produtoras maior que Xanthomonas. Cada linhagem foi ensaiada contra todas as outras da mesma espécie na detecção da produção de bacteriocinas; os dados para as linhagens produtoras estão nas Figuras 1, 2 e 3 . É possível verificar que não existe uma linhagem indicadora ideal, sensível a todas as produtoras, bem como também não existe uma produtora ideal, capaz de inibir todas as outras linhagens, exceto ela própria. Entretanto, linhagens como a P-44 e P-48 de Pseudomonas conseguem inibir 18 das 29 linhagens como ensaiadas. A P- 49 é, por outro lado, uma boa indicadora, pois foi sensível a 14 linhagens produtoras. Com relação à Erwinia, a linhagem E-16 inibe 14 das utilizadas e, em Xanthomonas a X-71 inibe 7 das 20 linhagens utilizadas.

Das linhagens produtoras, 5 delas (E-11, E$30, \mathrm{P}-49, \mathrm{P}-58$ e X-65) foram utilizadas para testes de verificação do efeito da concentração de ágar no meio, quantidade de meio por placa, e tempo de incubação. O meio sólido, sendo superior aos demais (Tabela 1), 
Tabela 1 - Número e porcentagem de linhagens bacteriocinogênicas encontradas em diferentes meios de cultura sólida.

\begin{tabular}{|c|c|c|c|c|c|c|c|}
\hline \multirow[t]{3}{*}{ Gênero } & \multirow{3}{*}{$\begin{array}{c}\mathrm{N}^{\circ} \text { Linhagens } \\
\text { Ensaiadas }\end{array}$} & \multicolumn{6}{|c|}{ Meios de Cultura } \\
\hline & & \multicolumn{2}{|c|}{523} & \multicolumn{2}{|c|}{ TYA } & \multicolumn{2}{|c|}{ NA } \\
\hline & & $\mathrm{N}^{\circ}$ & $\%$ & $N^{0}$ & $\%$ & $\mathrm{~N}^{\circ}$ & $\%$ \\
\hline Erwinia & 31 & 18 & 58,06 & 4 & 12,90 & 4 & 12,90 \\
\hline Pseudomonas & 29 & 23 & 79,31 & 10 & 34,48 & 7 & 24,13 \\
\hline Xanthomonas & 20 & 8 & 40,00 & 4 & 20,00 & 4 & 20,00 \\
\hline TOTAL & 80 & 49 & 61,25 & 18 & 22,22 & 15 & 18,51 \\
\hline
\end{tabular}

foi o utilizado. Os resultados (Tabelas 2 e 3), mostram que a concentração de $1,5 \%$ de ágar é a mais apropria$\mathrm{da}$, com produção de halos maiores e mais nítidos. A quantidade de meio nas placas praticamente não afetou os resultados e, foi verificado que, tempos maiores de incubação propiciaram um halo de inibição também maior e mais evidente.

Tabela 2 - Produção de bacteriocinas em diferentes concentrações de ágar e diferentes quantidades de meio adicionadas às placas (meio 523 sólido; média de 50 repetições; halo de inibição $\mathrm{em} \mathrm{mm}$ ).

\begin{tabular}{||ccccc||}
\hline $\begin{array}{c}\text { Linha- } \\
\text { gens }\end{array}$ & $\begin{array}{c}\text { Concentração de } \\
\text { Ágar (\%) }\end{array}$ & \multicolumn{2}{c|}{$\begin{array}{c}\text { Quantidade de } \\
\text { meio nas placas } \\
\text { (ml) }\end{array}$} \\
\cline { 2 - 5 } E-11 & 1,0 & 1,5 & 10,0 & 20,0 \\
E-30 & 0,9 & 1,7 & 1,7 & 1,6 \\
P-49 & 0,8 & 1,5 & 1,4 & 1,6 \\
P-58 & 0,7 & 1,3 & 1,4 & 1,1 \\
X-63 & 1,4 & 2,2 & 2,0 & 1,7 \\
\hline
\end{tabular}

A liberação de bacteriocinas no meio 523 líquido foi ensaiada em 10 linhagens produtoras e, apenas uma (P-58) liberou bacteriocina em meio líquido. A presença de halo de inibição revelou que o sobrenadante mesmo filtrado e com diluição de 1:10, ainda manteve sua atividade, mas, aeração e tempo de incubação não tiveram influência na detecção $e$ liberação de moléculas da bacteriocina.

Tabela 3 - Produção de bacteriocinas em diferentes tempos de incubação da linhagem produtora (halo de inibição em $\mathrm{mm}$ ).

\begin{tabular}{||cccc|}
\hline \multirow{2}{*}{ Linhagens } & \multicolumn{3}{c|}{ Tempo de Incubação (Horas) } \\
\cline { 2 - 4 } & 24 & 48 & 72 \\
E-11 & 1,0 & 2,3 & 3,2 \\
E-30 & 1,0 & 2,4 & 5,0 \\
P-49 & 2,0 & 5,0 & 6,4 \\
P-48 & 1,2 & 1,8 & 2,6 \\
X-65 & 0,8 & 1,5 & 2,0 \\
\hline
\end{tabular}

A influência da luz ultra-violeta na produção de bacteriocina foi verificada no meio 523 , em 3 linhagens (E-30, P-49 e P-58), tanto após irradiação em meio sólido como líquido. Foi usado também um controle (X-76) não produtor, que continuou não produzindo bacteriocina mesmo após irradiação com luz ultra-violeta. Os resultados indicam que, tanto em meio sólido como líquido, a influência da luz ultra-violeta em tornar o halo maior ou mais evidente, foi pequena ou nula na maioria dos casos (Tabelas 4 e 5). 


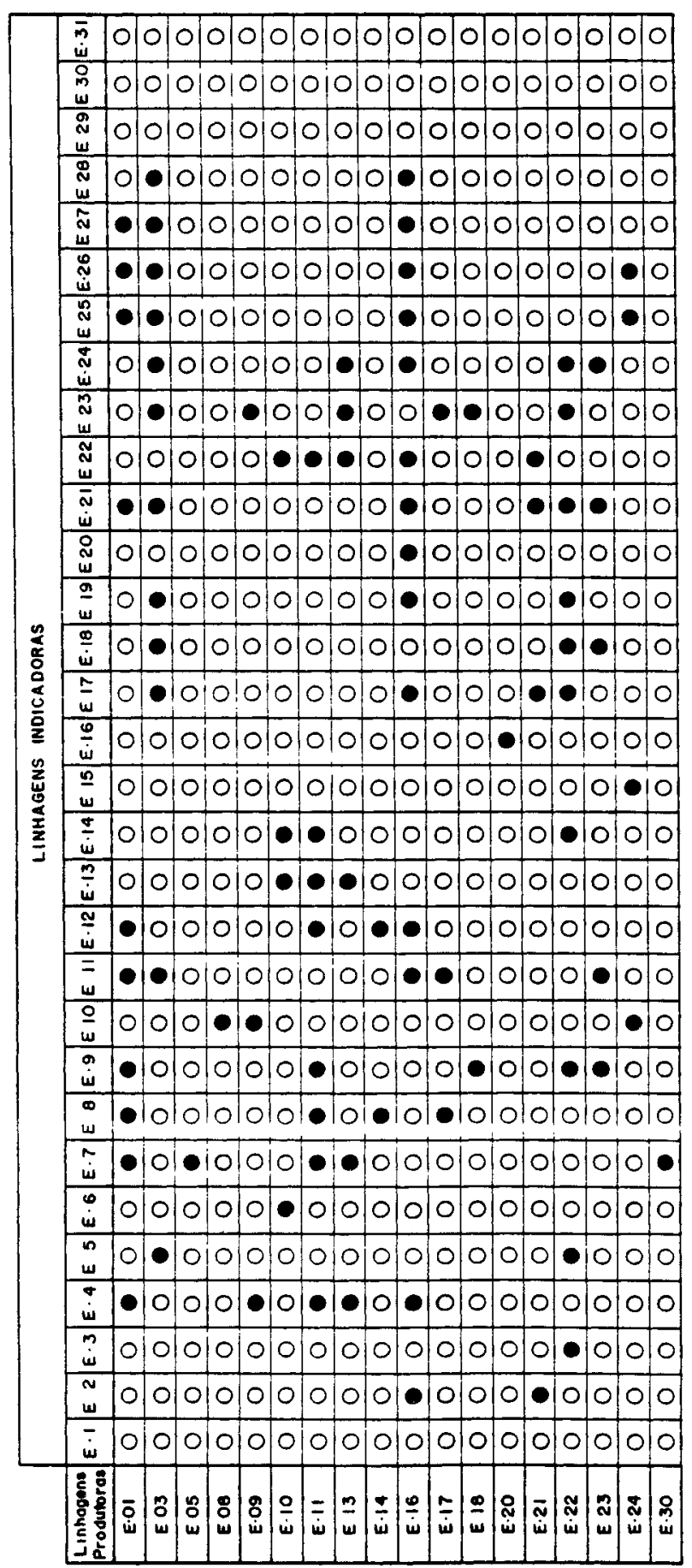

Figura 1 - Produção de bacteriocinas em Erwinia.

Obs: indica a presença de halo de inibição nas linhagens utilizadas como indicadoras; indica ausência de halo de inibição. 


\begin{tabular}{|c|c|c|c|c|c|c|c|c|c|c|c|c|c|c|c|c|c|c|c|c|c|c|c|c|}
\hline & & 0 & & O & & & 0 & 0 & 10 & 0 & $\bullet$ & 0 & 0 & 10 & 10 & & 0 & & & ol & ol & & & \\
\hline & & 0 & 0 & & 0 & 0 & 0 & 0 & 0 & 10 & 1 & 0 & 0 & 10 & 0 & 10 & 0 & 10 & Olo & ol & 0 & 0 & & \\
\hline & & 0 & 0 & 0 & 0 & 0 & 0 & 0 & 10 & 10 & & & 10 & 10 & 10 & 10 & o & & 10 & 0 & 0 & 0 & 0 & \\
\hline & & 0 & & 0 & O & 0 & 0 & 0 & 10 & 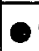 & • & 이 & 10 & 10 & & 0 & O & 10 & & 이 & - & 0 & 이 & \\
\hline & 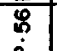 & & & 0 & 0 & c & & 0 & 10 & 10 & 10 & ol & 0 & 10 & 10 & إ) & o & 0 & old & 0 & 0 & 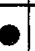 & 0 & \\
\hline & & 0 & - & 0 & 이 & $\bullet$ & 0 & 0 & 0 & 0 & $\bullet$ & 0 & - & 1 & 10 & $\bullet$ & O & 1 & 0 & 이 & $\bullet$ & ol & 0 & \\
\hline & & C & $\bullet$ & 0 & 이 & 0 & 0 & 0 & 0 & 10 & 10 & 10 & & ? & & - & - & 10 & & 0 & O & 0 & 0 & \\
\hline & & 0 & 0 & 0 & 이 & 0 & 0 & 10 & 10 & 0 & 10 & 0 & 0 & 10 & 0 & 0 & o & 10 & 0 & 0 & 0 & 0 & 0 & \\
\hline & 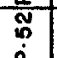 & C & - & 0 & 0 & 0 & 0 & 0 & 10 & 10 & 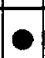 & 0 & 0 & le & 9 & 10 & 0 & 0 & 0 & 0 & - & 0 & 0 & C \\
\hline & & & & 0 & • & & - & 0 & 10 & 10 & 10 & | & 이 & 10 & 10 & 10 & 0 & 0 & & 0 & 0 & 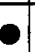 & 이 & \\
\hline & & 0 & 0 & 0 & 이 & 10 & 0 & 0 & - & $\bullet$ & 0 & $0 \mid$ & 10 & 0 & 0 & 0 & 0 & 0 & 0 & 0 & 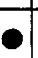 & 0 & 0 & \\
\hline & & C & 0 & 0 & 0 & 0 & 0 & 10 & 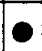 & $\bullet$ & $\bullet$ & & $\bullet$ & 0 & $\bullet$ & 10 & $\bullet$ & & & $\bullet$ & $\bullet$ & 0 & • & \\
\hline & & $c$ & - & 0 & 0 & 0 & 0 & 0 & 0 & $\bullet$ & 10 & $\bullet$ & 0 & 1 & 10 & 10 & $\bullet$ & 10 & 0 & •| & $\bullet$ & ol & 이 & \\
\hline & 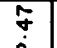 & 0 & $\bullet$ & 0 & 이 & 0 & 0 & 10 & 10 & 0 & 1 & 9 & - & 10 & - & 10 & 10 & 10 & 010 & 0 & 0 & 0 & - & \\
\hline & 8 & 0 & - & 0 & 10 & 0 & 0 & & 10 & 0 & 10 & 0 & 0 & 10 & - & 10 & 10 & $10 \mid$ & 10 & 0 & 0 & 0 & 이 & \\
\hline & & 0 & 0 & 0 & 0 & 10 & 0 & 0 & 0 & 0 & 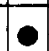 & 0 & & 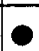 & 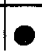 & $\bullet$ & 10 & 10 & 0 & 0 & $\bullet$ & 0 & 0 & \\
\hline & & 0 & O & 0 & & & 0 & & 10 & - & 0 & 0 & $\bullet$ & & 10 & 0 & 10 & & - & $\bullet$ & 0 & 0 & - & \\
\hline & & 0 & - & 0 & & 0 & 0 & & 0 & 10 & 10 & 10 & • & & $\bullet$ & & 10 & 10 & 10 & 0 & & 0 & & \\
\hline & & 0 & - & 0 & 0 & 0 & 0 & 0 & 10 & 10 & $\bullet$ & 10 & 10 & 0 & 1 & 10 & $\bullet$ & 10 & 0 & 0 & & 0 & & 0 \\
\hline & & 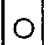 & 0 & 0 & & & 0 & 0 & 10 & 10 & 0 & $\bullet$ & 10 & 10 & 0 & 0 & 10 & 10 & 10 & 0 & 0 & 0 & 0 & $c$ \\
\hline & & 이 & 0 & 0 & 10 & 10 & 0 & 10 & 10 & 10 & e & 0 & 10 & & $\bullet$ & 1 & 10 & & 10 & 0 & 0 & 0 & & \\
\hline & & o & 0 & 0 & & 0 & 0 & 10 & 0 & 0 & 0 & 0 & 10 & 9 & • & 0 & 0 & 10 & 9 & $\bullet$ & 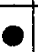 & 0 & - & \\
\hline & 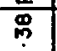 & of & - & & 0 & 0 & 0 & 10 & 0 & 0 & 0 & 10 & 0 & 0 & 0 & 10 & 0 & $10 \mid$ & 10 & 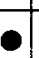 & 0 & $\bullet$ & 01 & 0 \\
\hline & & & 0 & & & & & & O & O & & 10 & 10 & 0 & & & & & 10 & 0 & & 0 & & \\
\hline & & & & & & & & & & & & & & & & & & & & & & & & \\
\hline & & 이 & 0 & 0 & & $\bullet$ & 0 & 10 & 0 & 0 & 10 & 0 & 1 & 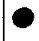 & 0 & $\bullet$ & 10 & 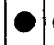 & $\bullet$ & $\bullet$ & 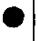 & 0 & 0 & \\
\hline & & 이 & - & 10 & O & $\bullet$ & 10 & 0 & 0 & 0 & 0 & 0 & 10 & 0 & - & - & 10 & 10 & 0 & 0 & 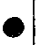 & 0 & 0 & 0 \\
\hline & & 0 & 0 & 0 & 0 & $\bullet$ & $0 \mid$ & 10 & 0 & 0 & 0 & 0 & 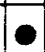 & 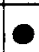 & 0 & $\bullet$ & 10 & & 0 & - & 0 & 0 & 0 & \\
\hline & & ol & 0 & 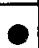 & & & 0 & & 10 & 0 & 0 & 10 & & 9 & 0 & 10 & -1 & 10 & 10 & $\bullet$ & & 0 & 0 & 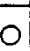 \\
\hline & & & & & & & & & & 0 & & 0 & & 0 & 0 & م & 10 & & & 0 & & & & \\
\hline & & & & & & & & & & & & & & & & & & & & & & & & \\
\hline & : & & & & m? & 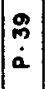 & $\left|\begin{array}{l}q \\
a \\
a\end{array}\right|$ & $\bar{a}$ & a & $\frac{5}{a}$ & $\frac{j}{\dot{a}}$ & $\left|\begin{array}{l}9 \\
+ \\
0\end{array}\right|$ & $\left|\begin{array}{l}0 \\
\dot{a}\end{array}\right|$ & $\frac{\mathfrak{T}}{\dot{a}}$ & $\frac{0}{+}$ & $\mid \begin{array}{l}q \\
\dot{a} \\
\dot{\alpha}\end{array}$ & $\left|\begin{array}{l}0 \\
0 \\
0\end{array}\right|$ & $\left|\begin{array}{l}\overline{0} \\
\dot{a}\end{array}\right|$ & $\mid \begin{array}{c}\tilde{0} \\
\dot{0} \\
\dot{0}\end{array}$ & 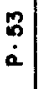 & $\mid \begin{array}{l}+ \\
\vdots \\
a\end{array}$ & $\mid \begin{array}{l}0 \\
0 \\
0\end{array}$ & $\mid \begin{array}{l}0 \\
0 \\
0 \\
0\end{array}$ & \\
\hline
\end{tabular}

Figura 2 - Produção de bacteriocinas em Pseudomonas.

Obs: indica a presença de halo de inibição nas linhagens utilizadas como indicadoras; indica ausência de halo de inibição. 


\begin{tabular}{|c|c|c|c|c|c|c|c|c|c|}
\hline & $\begin{array}{l}\stackrel{8}{\mathbf{g}} \\
\dot{x}\end{array}$ & 0 & 0 & 0 & 10 & 0 & 0 & 10 & 10 \\
\hline & $\stackrel{\mathscr{R}}{\dot{x}}$ & 0 & 0 & 0 & 0 & 10 & 0 & 10 & 10 \\
\hline & $\begin{array}{l}\stackrel{\Phi}{\dot{x}} \\
\dot{\boldsymbol{x}}\end{array}$ & 0 & 0 & 0 & 10 & 10 & 0 & 10 & 10 \\
\hline & $\stackrel{\sim}{\sim}$ & 0 & 0 & 0 & 0 & 10 & 0 & 10 & 10 \\
\hline & $\stackrel{\mathscr{P}}{\dot{\tau}}$ & 0 & 0 & 0 & 10 & 10 & 0 & 10 & 10 \\
\hline & $\stackrel{\mathbb{R}}{?}$ & 0 & 10 & 0 & 10 & 10 & 0 & 10 & 10 \\
\hline & $\underset{\dot{x}}{\dot{x}}$ & 0 & 0 & 0 & 0 & 0 & 0 & 10 & 10 \\
\hline & $\stackrel{\mathbb{R}}{\dot{\boldsymbol{x}}}$ & 10 & 0 & 0 & 0 & 0 & 0 & 10 & \\
\hline ㄴㅇㅁ & $\underset{\dot{\mathbb{x}}}{\stackrel{\mathbb{N}}{ }}$ & 10 & 0 & 0 & 10 & 10 & 0 & 10 & 10 \\
\hline 을 & $\dot{\tilde{T}}$ & 10 & 0 & 0 & 0 & 0 & 0 & 10 & 10 \\
\hline n & $\stackrel{P}{\stackrel{P}{\dot{\gamma}}}$ & 10 & 0 & 0 & 0 & 0 & 0 & 10 & 10 \\
\hline 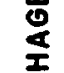 & $\stackrel{8}{\stackrel{8}{\dot{x}}}$ & 0 & 0 & 0 & 0 & $O$ & 0 & 10 & \\
\hline$\Xi$ & $\begin{array}{l}\mathscr{0} \\
\stackrel{0}{\check{亠}}\end{array}$ & 0 & 0 & 0 & 10 & 0 & 0 & 10 & 10 \\
\hline & $\overline{0}$ & 0 & 10 & 0 & 10 & 10 & 0 & 10 & 10 \\
\hline & $\begin{array}{l}0 \\
0 \\
\dot{0}\end{array}$ & 10 & 10 & 0 & 10 & 10 & 0 & 10 & 10 \\
\hline & $\begin{array}{l}0.0 \\
\dot{0} \\
\dot{x}\end{array}$ & 10 & 10 & 0 & 10 & 10 & 0 & 10 & 10 \\
\hline & $\underset{\bullet}{\dot{0}}$ & 10 & 10 & 0 & 0 & 0 & 0 & 10 & 10 \\
\hline & $\begin{array}{l}0 \\
0 \\
\dot{x}\end{array}$ & 0 & 0 & 0 & 0 & 0 & 0 & 10 & 0 \\
\hline & $\begin{array}{l}\tilde{N} \\
\dot{x}\end{array}$ & 0 & 0 & 0 & 0 & 10 & 0 & 10 & 10 \\
\hline & $\begin{array}{l}\bar{\varphi} \\
\dot{x}\end{array}$ & 0 & 0 & 0 & 0 & 10 & 0 & 10 & 10 \\
\hline & 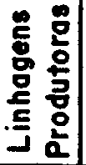 & $\begin{array}{l}\dot{\Xi} \\
\dot{x}\end{array}$ & $\begin{array}{l}\qquad 0 \\
\dot{x} \\
\dot{x}\end{array}$ & 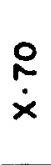 & $\overline{\check{x}}$ & $\underset{\dot{N}}{\dot{x}}$ & $\begin{array}{l}\stackrel{M}{\dot{x}} \\
\dot{\dot{x}}\end{array}$ & $\stackrel{n}{\dot{x}}$ & $\begin{array}{l}\tilde{\lambda} \\
\dot{x}\end{array}$ \\
\hline
\end{tabular}

Figura 3 - Produção de bacteriocinas em Xanthomonas.

Obs: indica a presença de halo de inibição nas linhagens utilizadas como indicadoras; indica ausência de halo de inibição. 
Tabela 4 - Produção de bacteriocinas após tratamento com luz ultra-violeta em meio líquido (média de 50 repetições; halo de inibição em $\mathrm{mm})$.

\begin{tabular}{||cccc|}
\hline $\begin{array}{c}\text { Tempo de irra- } \\
\text { diação (seg.) }\end{array}$ & \multicolumn{3}{c|}{ Linhagens } \\
\cline { 2 - 4 } & E-30 & P-49 & P-58 \\
0 & 0,7 & 2,0 & 0,6 \\
10 & 0,6 & 2,7 & 1,5 \\
20 & 0,2 & 3,0 & 1,0 \\
30 & 0,4 & 3,2 & 1,6 \\
\hline
\end{tabular}

Tabela 5 - Produção de bacteriocinas após tratamento com luz ultra-violeta em meio sólido (tamanho dos halos de inibição em mm).

\begin{tabular}{||cccccccc||}
\hline \multirow{2}{*}{$\begin{array}{l}\text { Tempo } \\
\text { de irra- } \\
\text { diaçã } \\
\text { (seg.) }\end{array}$} & \multicolumn{1}{c}{ Linhagens } \\
\cline { 2 - 8 } & & \multicolumn{1}{c}{ E-30 } & \multicolumn{2}{c|}{ P-49 } & \multicolumn{2}{c|}{ P-58 } \\
\cline { 2 - 8 } & $2 h$ & $24 h$ & $2 h$ & $24 h$ & $2 h$ & $24 h$ \\
0 & 1,6 & 3,0 & 1,2 & 2,2 & 1,0 & 1,6 \\
10 & 1,6 & 2,7 & 1,3 & 2,5 & 1,1 & 1,9 \\
20 & 0,7 & 1,5 & 1,3 & 2,5 & 1,4 & 2,7 \\
30 & 1,1 & 2,3 & 1,4 & 2,9 & 1,5 & 3,2 \\
\hline
\end{tabular}

\section{DISCUSSÃO}

O número de linhagens produtoras de bacteriocinas nos 3 gêneros ensaiados $\varepsilon$ similar ao encontrado por outros autores. Assim, HAMON \& PÉRON (1961), obtiveram 77,3\% de amostras de Erwinia produtoras e STANGUELLINI et al., (1977), no mesmo gênero, obtiveram $83,3 \%$ de bacteriocinogênicas. Para Pseudomonas, os dados de HAMON et al., (1961) são de $95 \%$ de produtoras em $P$. pyocianea e $44 \%$ em $P$. fluorescens. VIDAVER et al., (1972), encontraram 100\% de produtoras em $P$. syringae, $55 \%$ em $P$. glycinae e $8 \%$ em $P$. phaseolicola. Para Xanthomonas, SANTOS (1979), encontrou valores de $47 \%$ de produtoras em $X$. campestris.

O meio 523 sólido foi o mais eficiente na detecção de linhagens produtoras. De fato, todas as linhagens detectadas como produtoras nos outros meios usados (NL e TYA), também tiveram produção em meio 523. As causas podem ser diversas mas, ressaltase que o meio 523 é o mais complexo dos 3 utilizados. Talvez, a presença de caseína hidrolisada possa ser a responsável pela superioridade do meio 523 , como citado por HAMON (1955) e HERTMAN \& BENGURIOL (1958). Com relação à quantidade de meio nas placas, os dados não evidenciaram grande diferença, mas a concentração de ágar é crucial para se obter um melhor resultado. A maior viscosidade do meio já foi relatada como otimizadora da visualização do halo de inibição (KESTRUP \& GIBBONS, 1969; GROSS \& VIDAVER, 1978).

Também, maior tempo de incubação facilita a leitura de halos, o que também já havia sido verificado por VIDAVER et al., (1972).

A liberação de bacteriocina em meio líquido foi positiva em apenas um caso e, aeração não influiu na liberação. A dificuldade de obtenção de bacteriocinas liberadas em meio líquido já havia sido observada (GROSS \& VIDAVER, 1978 e HIRSH, 1979).

Com relação à luz ultravioleta, células irradiadas em meio líquido deram pequeno aumento de indução em duas linhagens $\mathrm{e}$, até possível diminuição em uma terceira. Tanto em meio líquido como sólido, sugere-se que, se irradiação for utilizada, pequenas doses seriam mais apropriadas. Resultados semelhantes foram obtidos por vários autores, por exemplo, HONGO et al., (1968).

Com base nos resultados obtidos, sugere-se que a busca de linhagens produtoras de bacteriocinas, pelo menos nos 3 gêneros de bactérias fitopatogênicas ensaiadas, deva ser feita em meio sólido 523 , utilizando-se 1,5\% de ágar no meio sólido, tempo de incubação de 72 horas e, se irradiação ultra-violeta for utilizada, esta pode ser feita por um curto período de tempo, em meio sólido. Linhagens indicadoras como P-49 podem ser utilizadas na detecção de linhagens produtoras mas, o melhor, seria o uso de muitas linhagens para obtenção de resultados mais confiáveis. Deve-se também levar em conta que, alguns dos fatores ensaiados como meio de cultura, concentração de ágar e tempo de incubação valem para todos os gêneros e linhagens utilizadas. Outras, como a luz ultra-violeta, podem variar de acordo com a linhagem ou espécie bacteriana. 


\section{AGRADECIMENTOS}

Agradecimentos são devidos ao CNPq (bolsa doutorado) e à CAPES (bolsa dedicação acadêmica), concedidas ao primeiro e segundo autores, respectivamente.

\section{REFERÊNCIAS BIBLIOGRÁFICAS}

AZEVEDO, J.L. Genética de Microrganismos em Biotecnologia e Engenharia Genética, Piracicaba, Editora FEALQ, 1985, 173 p.

AZEVEDo, J.L. \& COSTA, S.o.P. Exercícios práticos de Genética, Cia. Editora Nacional e Editora Universidade de São Paulo, 1973, 288 p.

Costa, S.o.P. Genética Molecular e de Microrganismos, São Paulo, Editora Manole, $1987,559 \mathrm{p}$.

DAY, M.J. Plasmids, London, Edward Arnold, 1990, $50 \mathrm{p}$.

GROSS, D.C. \& VIDAVER, A.K. Bacteriocins of phytopathogenic Corynebacterium species. Canadian Journal of Microbiology, 25 : 367-374, 1979.

HAMON, Y. Étude d'une colicine elaboreé par une culture de $S$. paratyphi B. Annales de L'Institute Pasteur, 88 : 193-204, 1985.

HAMON, Y. \& PÉRON, Y. Las proprietés antagonistes réciproques parmi les Erwinia. Discussion de la position taxonomique de ce genre. Comptes Rendus Hebdomadaires des Śrances de l'Academie des Sciences, 253 : 913915, 1961.

HAMON, Y.; VÉRON, M. \& PÉRON, Y. Contribuition a l'étude de propriétés lysogènes et bactériocinogènes dans le genre Pseudomonas. Annales de l'Institute Pasteur, 101 : 738753,1961 .

HERTMAN, I. \& BEN-GURIOL, R. A study on pesticin byosynthesis. Journal of General Microbiology, 21 : 135-143, 1958.

HIRSH, P.R. Plasmid-determined bacteriocin production by Rhizobium leguminosarum. Journal of General Microbiology, 3:219-228, 1979.

HONGO, M.; MURATA, A.; OGATA, S.; KONO, K.; KATO, T. Characterization of a temperate phage and four bacteriocins produced by nonpathogenic Clostridium species. Agricultural and Biological Chemistry, 32 : 773-780, 1968.

KADO, C.I. \& HESKET, M.G. Selective media for isolation of Agrobacterium, Corynebacterium, Erwinia, Pseudomonas and Xanthomonas. Phytopathology, 60 : 969-976, 1970.

KELSTRUP, J. \& GIBBONS, R.J. Bacteriocins from human and rodent Streptococci. Archives of Oral Biology, 1 : 251-258, 1969.

PRIMROSE, S.B. Modern Biotechnology, Oxford, Blackwell Scientific Publications, 1987, 176 p.

ROITMAN, I.; TRAVASSOS, L.R. \& AZEVEDO, J.L. Tratado de Microbiologia, vol. III. São Paulo, Editora Manole, 1992 (no prelo).

SANTOS, M.M.L.S. Produção de bacteriocinas e resistência a antibioticos em Xanthomonas campestris (Pammel) Dowson. Piracicaba, ESALQ/USP, 1979. 81 p. Dissertação de Mestrado.

STANGHELLINI, M.E.; SANDS, D.C.; KRONLAND, W.C.; MENDONÇA, M.M. Serological and physiological differentiation among isolates of Erwinia carotovora from potato and sugarbeet. Phytopathology, 67 : 1178-1182, 1977.

VIDAVER, A.K.; MATHYS, M.L.; THOMAS, M.E.; SCHUSTER, M.L. Bacteriocins of the phytopathogens Pseudomonassyringae, P. glycinea and $P$. phaseolicola. Canadian Journal of Microbiology, 18 : 705,713, 1972.

Trabalho entregue para publicação em 06.07.1992 Trabalho aprovado para publicação em 13.07.1992 